\title{
Gender Dan Leadership Aspiration: Pengaruh Dari Communal Orientation Dan Organizational Identification
}

\author{
Febiola dan Ronnie Resdianto Masman \\ Program Studi Manajemen, Fakultas Ekonomi dan Bisnis \\ Universitas Tarumanagara, Jakarta \\ Email:febiolazipora@gmail.com
}

\begin{abstract}
This research was conducted in order to determine and understand the impact of gender toward leadership aspiration mediated by communal orientation, and organizational identification toward leadership aspiration and the moderating effect of it in the environment of coffee shop employee based in North Jakarta. This research implements survey method, in which questionnaires were used as tools to collect the data needed for this research. A total of 80 respondents participated in this research, were then analysed using PLS-SEM method using SmartPLS 3.2.7 Software. Based on the results of the data analysis, it was found that gender is a significant predictor toward leadership aspiration mediated by communal orientation, and organizational identification is a significant predictor toward leadership aspiration and has a moderating effect toward the impact of communal orientation toward leadership aspiration. Theoretical and practical contributions are discussed.
\end{abstract}

Keywords: Leadership Aspiration, Organizational Identification, Communal Orientation, Gender, SEM-PLS Method.

Abstrak: Penelitian ini dilakukan guna mengetahui dan memahami pengaruh gender terhadap aspirasi kepemimpinan yang dimediasi oleh orientasi komunal, dan identifikasi organisasi terhadap aspirasi kepemimpinan serta efek moderasinya di lingkungan pekerja kedai kopi di Jakarta Utara. Penelitian ini mengimplementasikan metode survei, dimana kuesioner digunakan sebagai alat untuk mengumpulkan data dari responden. Sebanyak 80 responden berpartisipasi pada penelitian ini, kemudian diolah dengan metode PLS-SEM dengan bantuan perangkat lunak SmartPLS versi 3.2.7. Berdasarkan hasil analisis data, dapat disimpulkan bahwa gender adalah prediktor yang signifikan terhadap aspirasi kepemimpinan yang dimediasi oleh orientasi komunal, dan identifikasi organisasi adalah prediktor yang signifikan terhadap aspirasi kepemimpinan dan memiliki efek moderasi terhadap hubungan antara orientasi komunal dan aspirasi kepemimpinan. Kontribusi teori dan praktik dibahas dalam penelitian ini.

Kata Kunci: Aspirasi Kepemimpinan, Identifikasi Organisasi, Orientasi Komunal, Gender, Metode PLS-SEM

\section{LATAR BELAKANG}

Semakin tinggi posisi karir seseorang, semakin tinggi pula tingkat kemampuan kepemimpinan (leadership) yang harus dimilikinya. Hal tersebut dikarenakan semakin tinggi posisi karir seseorang, maka akan semakin banyak orang yang menduduki posisi 
sebagai bawahan orang tersebut. Seorang atasan harus mampu untuk memimpin bawahannya. Menurut kornferry.com (2016), saat ini organisasi sedang menghadapi krisis leadership. Hanya sekitar 17 persen dari para eksekutif organisasi yang yakin bahwa pemimpin organisasi mereka mempunyai kemampuan leadership yang tepat dan diperlukan oleh organisasi. Mayoritas eksekutif organisasi mengharapkan agar manajer mereka mempunyai kinerja yang optimal dalam waktu enam bulan, namun mempunyai jiwa leadership merupakan suatu hal yang sulit.

Aspirasi merupakan sikap leadership yang seringkali diabaikan dan kurang disadari oleh masyarakat. Maka dari itu, semua pemimpin yang baik adalah sosok yang mempunyai aspirasi atau keinginan dan cita-cita. Mereka mempunyai cita-cita untuk menjadi pribadi yang lebih baik yang bertumbuh serta dapat mengembangkan organisasinya agar menjadi lebih baik. Setiap pemimpin pertama-tama harus bercita-cita untuk menjadi seorang pemimpin. Mereka harus mempunyai impian atas masa depan yang lebih baik dan keinginan untuk menghasilkan dampak yang baik pula. Aspirasi merupakan awal dari leadership yang baik. Maka dari itu, pemimpin yang baik harus mempunyai leadership aspiration yang tinggi.

Salah satu faktor yang menstimulasi leadership aspiration adalah organizational identification. Individu yang mempunyai hubungan yang erat dan mempunyai tujuan yang sama dengan organisasi tempat individu tersebut berada, akan mempunyai cita-cita untuk menjadi seorang pemimpin dan memimpin organisasinya. Hubungan yang erat dalam individu dapat diperkuat oleh communal orientation seseorang. Sikap-sikap dari communal orientation ini dapat membuat individu mempunyai perasaan lebih terikat dan memiliki hubungan yang lebih erat dengan organisasinya. Di dalam ranah psikologi, terdapat istilah agentik dan komunal. Apabila seseorang yang berorientasi agentik cenderung untuk lebih bersifat ambisius, kompetitif, dan dominan (Gebauer et al., 2013), maka seseorang yang berorientasi komunal akan cenderung untuk lebih bersifat penyayang, perhatian, berbelas kasih, sensitif, dan pengertian (Gebauer et al., 2013). Pria cenderung lebih kuat dalam berorientasi agentik, sedangkan wanita cenderung lebih kuat dalam berorientasi komunal (Eagly, 1987).

Perbedaan gender, yakni pria dan wanita dalam menduduki posisi leader merupakan hal yang tidak dapat dihindari dalam lingkungan ketenagakerjaan, termasuk lingkungan pekerja kedai kopi sekalipun. Menurut International Coffee Organization, 20 hingga 30 persen kebun kopi dikelola oleh wanita, dan lebih dari 70 persen buruh di industri kopi adalah wanita (kumparan.com). Hal tersebut berarti bahwa tingkat leadership wanita dalam industri kedai kopi hanyalah sebatas 20 hingga 30 persen saja.

Berdasarkan latar belakang yang telah diuraikan, terdapat beberapa rumusan masalah antara lain: (1) Apakah gender mempengaruhi communal orientation? (2) Apakah communal orientation mempengaruhi leadership aspiration? (3) Apakah gender memiliki efek tidak langsung terhadap leadership aspiration yang dimediasi oleh communal orientation? (4) Apakah organizational identification mempengaruhi leadership aspiration? (5) Apakah organizational identification memoderasi hubungan antara communal orientation dan leadership aspiration?

Berdasarkan rumusan masalah yang ada, tujuan dari penelitian ini adalah untuk mengetahui secara empiris tentang: (1) Pengaruh gender terhadap communal orientation, (2) Pengaruh communal orientation terhadap leadership aspiration, (3) Efek tidak langsung dari gender terhadap leadership aspiration dengan mediasi oleh communal orientation, (4) Pengaruh organizational identification terhadap leadership aspiration, dan 
(5) Efek moderasi dari organizational identification terhadap hubungan antara communal orientation dan leadership aspiration. Melalui penelitian ini, diharapkan dapat menjadi landasan bagi para pemilik perusahaan untuk melatih dan menetapkan pemimpin yang terbaik berdasarkan leadership aspiration dan faktor-faktor yang mempengaruhinya seperti gender, communal orientation, dan organizational identification .

\section{KAJIAN TEORI}

Ada banyak hal yang dapat membuat seorang pemimpin memiliki sikap kepemimpinan yang baik. Para teoritisi yang mendalami berbagai aspek, masalah, dan pendekatan tentang kepemimpinan yang efektif pada umumnya telah sepakat bahwa salah satu pendekatan yang dapat digunakan adalah dengan menganalisis kepemimpinan berdasarkan ciri-ciri ideal yang menjadi idaman setiap orang yang menduduki jabatan pimpinan.

Traits Theory, atau yang disebut sebagai teori tentang analisis kepemimpinan berdasarkan ciri adalah pembahasan secara teoritikal menyangkut ciri-ciri yang bersifat ideal yang perlu diusahakan kepemilikannya terus-menerus oleh setiap orang yang mendapat kesempatan menjadi pimpinan (Siagian P., 1994).

Pria dan wanita cenderung memiliki ciri-ciri gender yang berbeda. Pria cenderung untuk bersikap agentic orientation, sedangkan wanita cenderung memiliki communal orientation yang lebih besar (Abele, 2003; Bakan, 1966; Eagly, 1987). Sejalan dengan communal orientation, seperti berorientasi pada hubungan, perhatian, dan kepedulian (Gebauer et al., 2013; Lyness dan Heilman, 2006), wanita cenderung untuk mencari pekerjaan yang memberikan peluang untuk bekerja dengan orang-orang dan membantu orang lain (Eagly dan Carli, 2007). Leadership, dan juga leadership aspiration, berbicara tentang keinginan memotivasi dan membantu orang lain untuk secara kolaboratif mencapai tujuan organisasi (Bass dan Stogdill, 1990; van Knippenberg et al., 2004). Dengan demikian, dapat diambil hipotesis sebagai berikut:

H1. Gender memiliki pengaruh yang positif terhadap communal orientation.

H2. Communal orientation memiliki pengaruh yang positif terhadap leadership aspiration.

H3. Gender memiliki pengaruh yang positif terhadap leadership aspiration melalui mediasi dari communal orientation.

H4. Individu komunal biasanya menggunakan hubungan dengan kelompok untuk memenuhi kebutuhan mereka dalam mencari koneksi atau identifikasi sosial (Flum, 2001; Locke et al., 2012, Wiggins, 1991).

H5. Salah satu contoh dari identifikasi sosial adalah organizational identification, yang menyiratkan bahwa individu menginternalisasi atribut organisasi sebagai milik mereka (Mael dan Ashforth, 1995; Ashforth et al., 2008). Karena organizational identification terkait dengan kebutuhan untuk menjadi bagian (Ashforth, 2001; Ashforth et al., 2008) dan karena kebutuhan untuk menjadi bagian tersebut dikaitkan dengan leadership aspiration wanita, diperkirakan bahwa organizational identification adalah isyarat yang sangat relevan untuk merangsang communal orientation wanita terhadap leadership aspiration. Secara khusus, diharapkan bahwa organizational identification yang tinggi merangsang leadership aspiration individu komunal, karena identifikasi terkait dengan motivasi untuk melayani kepentingan komunal dan karena kepemimpinan itu sendiri umumnya terkait dengan memotivasi karyawan untuk 
bekerja menuju kesuksesan bersama (Bass dan Stogdill, 1990; Burns, 1978). Dengan demikian, dapat diambil hipotesis sebagai berikut:

H6. Organizational identification memiliki pengaruh yang positif terhadap leadership aspiration.

H7. Organizational identification memoderasi hubungan communal orientation dan leadership aspiration.

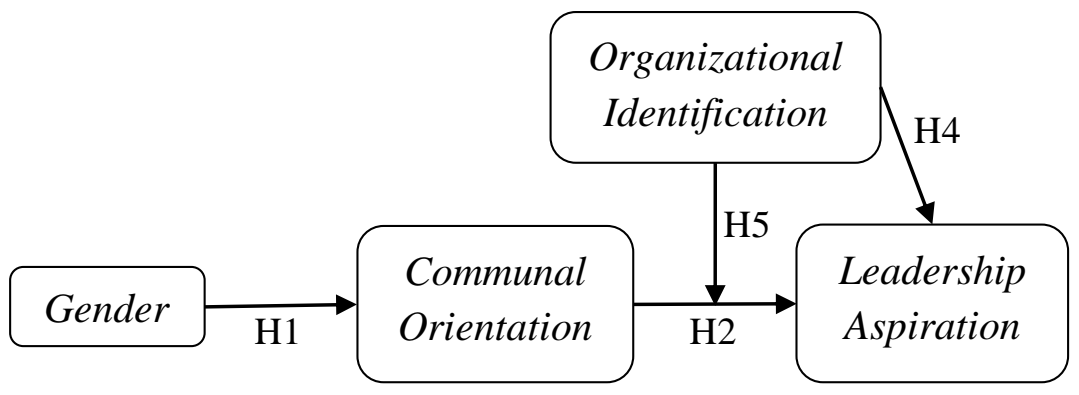

Gambar 1. Model Penelitian

\section{METODOLOGI}

Penelitian ini menggunakan single cross-sectional. Melalui descriptive research design, peneliti berharap untuk dapat mengetahui hubungan dan mendapatkan informasi secara akurat, serta dapat mengetahui korelasi dari gender terhadap leadership aspiration dengan mediasi dari communal orientation dan moderasi dari organizational identification. Teknik pemilihan sampel di penelitian ini adalah simple random sampling. Jumlah sampel dalam penelitian ini adalah 80 sampel, dengan kriteria responden tersebut adalah seorang pekerja kedai kopi di Jakarta Utara, khususnya di area Pluit dan Muara Karang.

Seluruh pengukuran variabel (kecuali gender) menggunakan skala semantik diferensial dengan 10 titik. Variabel leadership aspiration menggunakan 17 indikator yang dikemukakan oleh Gray dan O'Brien (2007). Variabel organizational identification menggunakan 6 indikator yang dikemukakan oleh Mael dan Ashforth (1992). Variabel communal orientation menggunakan 10 indikator yang dikemukakan oleh Gebauer et al. (2013). Variabel gender menggunakan skala interval, dengan angka 1 sebagai pria dan angka 2 sebagai wanita.

Penelitian ini menggunakan teknik analisis data Structural Equation Modelling (SEM), dengan Variance-Based (PLS-SEM) dan menggunakan bantuan perangkat lunak SmartPLS Versi 3.2.7. SEM membagi analisisnya menjadi dua bagian yaitu outer model dan inner model. Analisis validitas dan reliabilitas merupakan bagian dari outer model, yang diukur dengan menggunakan convergent validity, discriminant validity, dan uji reliabilitas. Kriteria dari pengujian outer model dijelaskan pada Tabel 1. Inner model analysis dapat dilakukan hanya apabila seluruh variabel dan indikator yang digunakan untuk penelitian telah memenuhi lolos uji validitas dan reliabilitas. Henseler et al. (2009) mengemukakan bahwa terdapat beberapa kriteria yang dapat digunakan oleh seorang peneliti untuk melakukan analisis model struktural terhadap model penelitian yang sedang digunakan. Kriteria tersebut ditunjukkan pada Tabel 2.

Hair et al. (2011) mengemukakan bahwa pengujian hipotesis pada penelitian yang menggunakan metode PLS-SEM dapat dilakukan dengan melihat nilai $t$-statistic yang muncul pada path analysis, dengan menggunakan metode bootstraping pada SmartPLS. 
Penelitian ini menggunakan taraf signifikansi sebesar 0,05. Dalam hal ini, terdapat dua kemungkinan yang dapat terjadi terhadap hipotesis penelitian. Pertama, hipotesis penelitian ditolak apabila nilai $t$-statistics yang muncul tidak melebihi 1,96 dan nilai $p$-value lebih besar dari 0,05 . Kedua, hipotesis penelitian tidak ditolak atau diterima apabila nilai $t$ statistics yang muncul lebih dari 1,96 dan nilai $p$-value tidak melebihi 0,05 .

Tabel 1. Kriteria Pengujian Outer Model

\begin{tabular}{|c|l|c|l|}
\hline Uji Outer Model & \multicolumn{1}{|c|}{ Kriteria } & Cut-Off Value & \multicolumn{1}{|c|}{ Sumber } \\
\hline $\begin{array}{c}\text { Convergent } \\
\text { Validity }\end{array}$ & Nilai outer loadings setiap item & $>0,50$ & $\begin{array}{l}\text { Barclay dan } \\
\text { Thompson (1995); } \\
\text { Chin (1998) }\end{array}$ \\
\cline { 2 - 4 } & $\begin{array}{l}\text { Nilai Average Extracted } \\
\text { Variance (AVE) setiap variabel }\end{array}$ & $>0,50$ & Hair et al. (2011) \\
\hline $\begin{array}{c}\text { Discriminant } \\
\text { Validity }\end{array}$ & $\begin{array}{l}\text { Nilai akar kuadrat AVE setiap } \\
\text { variabel }\end{array}$ & $\begin{array}{c}>\text { Korelasi } \\
\text { antarvariabel }\end{array}$ & Hair et al. (2011); \\
\hline \multirow{2}{*}{ Reliabilitas } & Composite Reliability & $>0,70$ & $\begin{array}{l}\text { Hair } \text { et al. } \text { (2014); } \\
\text { Henseler } \text { et al. }\end{array}$ \\
\cline { 2 - 4 }$(2009)$
\end{tabular}

Sumber: Peterson (1994), Henseler et al. (2009), Hair et al. (2011)

Tabel 2. Kriteria Pengujian Inner Model

\begin{tabular}{|c|c|c|}
\hline Kriteria & Penjelasan Hasil & Sumber \\
\hline $\begin{array}{l}\text { Nilai } R \text {-Square } \\
\quad\left(\mathrm{R}^{2}\right)\end{array}$ & $\begin{array}{ll}\leq 0.25 & : \text { Pengaruh substansial } \\
\geq 0.26-\leq 0.74 & : \text { Pengaruh moderat } \\
\geq 0.75 & : \text { Pengaruh kuat }\end{array}$ & Hair et al. (2011) \\
\hline $\begin{array}{c}\text { Nilai } \\
\text { Predictive } \\
\text { Relevance }\left(\mathrm{Q}^{2}\right)\end{array}$ & $\begin{array}{l}<0: \text { Variabel tidak dapat memprediksi model dengan } \\
\text { baik } \\
>0: \text { Variabel dapat memprediksi model dengan baik }\end{array}$ & $\begin{array}{l}\text { Hair et al. (2011); } \\
\text { Henseler et al. } \\
(2009)\end{array}$ \\
\hline $\begin{array}{l}\text { Nilai } \\
\text { Signifikansi } \\
\text { Variabel }\end{array}$ & $\begin{array}{l}\text { Nilat } \mathrm{t}>1,65(\text { Untuk } \alpha=0,1) \\
\text { Nilai } \mathrm{t}>1,96(\text { Untuk } \alpha=0,05) \\
\text { Nilai } \mathrm{t}>2,58(\text { Untuk } \alpha=0,01)\end{array}$ & Hair et al. (2011) \\
\hline
\end{tabular}

Sumber: Henseler et al. (2009) dan Hair et al. (2011)

\section{HASIL ANALISIS DATA}

Dari 80 responden, 40 responden adalah wanita dan sisanya pria. Sebagian besar responden berusia 19 tahun sampai 24 tahun (51 orang, 64\%) dan sisanya berusia 16 tahun sampai 18 tahun (8 orang, 10\%), 25 tahun sampai 30 tahun (10 orang, 12\%) dan 31 tahun sampai 38 tahun (11 orang, 14\%). Pendidikan terakhir sebagian responden adalah SMA/Sederajat (50 orang, 62\%) dan sisanya S1 (24 orang, 30\%) dan D3 (6 orang, 8\%). Status pernikahan sebagian besar responden adalah belum menikah (70 orang, 87\%) dan sisanya sudah menikah namun belum memiliki anak (7 orang, 9\%) dan sudah menikah dan sudah memiliki anak (3 orang, 4\%). Posisi pekerjaan sebagian besar responden adalah 
barista junior (45 orang, 56\%) dan sisanya adalah manager (13 orang, 16\%), barista senior (11 orang, 14\%) dan supervisor (11 orang, 14\%). Durasi lama bekerja sebagian besar responden adalah kurang dari 3 bulan (30 orang, 38\%) dan sisanya 3 bulan sampai 1 tahun (29 orang, 36\%), lebih dari 2 tahun (16 orang, 20\%) dan antara 1 tahun sampai 2 tahun (5 orang, $6 \%$ ).

Hasil analisis discriminant validity ditunjukkan oleh Tabel 3, sementara untuk hasil analisis convergent validity dan uji reliabilitas ditunjukkan oleh Tabel 4. Tabel 3 menunjukkan hasil analisis factor loadings, Average Variance Extracted (AVE), composite reliability, maupun Cronbach's Alpha. Tabel 4 menunjukkan nilai akar kuadrat AVE dari masing-masing variabel lebih besar daripada korelasi antarvariabel lainnya. Berdasarkan hasil analisis convergent validity, reliabilitas, dan discriminant validity, dapat disimpulkan bahwa seluruh variabel di dalam penelitian ini yakni Leadership Aspiration, Organizational Identification, Communal Orientation, Gender, dan efek moderasi telah memenuhi syarat validitas dan reliabilitas.

Analisis data dalam penelitian ini meliputi inner model analysis, mediation analysis, dan pengujian hipotesis. Berdasarkan hasil analisis $\mathrm{R}^{2}$ pada Tabel 5 , variabel communal orientation memiliki nilai $\mathrm{R}^{2}$ sebesar 0,083 . Artinya, sebesar $8,3 \%$ variabel communal orientation dapat dijelaskan oleh variabel gender, sementara sisanya 91,7\% dapat dijelaskan oleh variabel lainnya di luar penelitian ini. Leadership aspiration memiliki nilai $\mathrm{R}^{2}$ sebesar 0,664. Artinya, sebesar 66,4\% variabel leadership aspiration dapat dijelaskan oleh variabel communal orientation dan organizational identification, sementara sisanya $33,6 \%$ dapat dijelaskan oleh variabel lainnya di luar penelitian ini. Tabel 5 juga menunjukkan hasil analisis $\mathrm{Q}^{2}$. Nilai $\mathrm{Q}^{2}$ untuk leadership aspiration adalah sebesar 0,346 dan untuk communal orientation adalah 0,040. Dengan demikian, variabel-variabel endogen dinyatakan mampu untuk memprediksi model penelitian ini dengan baik karena memiliki nilai $\mathrm{Q}^{2}$ lebih besar dari 0 .

Nilai $t$-statistics dari hubungan antara gender dan communal orientation telah memenuhi syarat signifikansi, dengan demikian, H1 tidak ditolak. Nilai $t$-statistics dari hubungan antara communal orientation dan leadership aspiration, organizational identification dengan leadership aspiration, serta efek moderasi dari organizational identification terhadap hubungan communal orientation dengan leadership aspiration telah memenuhi syarat signifikansi, dengan demikian, H2, H3, dan $\mathrm{H} 4$ tidak ditolak. Nilai $t$ statistics pada hubungan antara variabel gender dengan variabel leadership aspiration melalui variabel communal orientation telah melebihi cut-off value, yakni di atas 1,96. Dengan demikian, H5 tidak ditolak.

Tabel 3. Hasil Analisis Fornell-Larcker (Discriminant Validity)

\begin{tabular}{|l|c|c|c|c|c|}
\hline & CO & G & LA & M & OI \\
\hline $\begin{array}{l}\text { Communal } \\
\text { Orientation }\end{array}$ & $\mathbf{0 . 7 5 0}$ & & & & \\
\hline Gender & 0.288 & $\mathbf{1 . 0 0 0}$ & & & \\
\hline $\begin{array}{l}\text { Leadership } \\
\text { Aspiration }\end{array}$ & 0.526 & 0.032 & $\mathbf{0 . 7 6 2}$ & & \\
\hline Efek Moderasi & -0.099 & 0.049 & -0.255 & $\mathbf{1 . 0 0 0}$ & -0.006 \\
\hline $\begin{array}{l}\text { Organizational } \\
\text { Identification }\end{array}$ & 0.291 & -0.090 & 0.711 & $\mathbf{0 . 7 8 6}$ \\
\hline
\end{tabular}


Tabel 4. Hasil Analisis Convergent Validity dan Reliabilitas

\begin{tabular}{|c|c|c|c|c|c|}
\hline Variabel & Indikator & $\begin{array}{c}\text { Outer } \\
\text { Loadings }\end{array}$ & AVE & $\begin{array}{l}\text { Composite } \\
\text { Reliability }\end{array}$ & $\begin{array}{c}\text { Crombach's } \\
\text { Alpha }\end{array}$ \\
\hline \multirow{12}{*}{$\begin{array}{l}\text { Leadership } \\
\text { Aspiration }\end{array}$} & LA1 & 0.696 & \multirow{12}{*}{0.581} & \multirow{12}{*}{0.943} & \multirow{12}{*}{0.933} \\
\hline & LA2 & 0.642 & & & \\
\hline & LA5 & 0.647 & & & \\
\hline & LA7 & 0.825 & & & \\
\hline & LA8 & 0.764 & & & \\
\hline & LA9 & 0.854 & & & \\
\hline & LA10 & 0.778 & & & \\
\hline & LA11 & 0.805 & & & \\
\hline & LA12 & 0.783 & & & \\
\hline & LA13 & 0.877 & & & \\
\hline & LA14 & 0.758 & & & \\
\hline & LA17 & 0.673 & & & \\
\hline \multirow{6}{*}{$\begin{array}{l}\text { Organizational } \\
\text { Identification }\end{array}$} & OI1 & 0.810 & \multirow{6}{*}{0.618} & \multirow{6}{*}{0.906} & \multirow{6}{*}{0.877} \\
\hline & $\mathrm{OI} 2$ & 0.842 & & & \\
\hline & $\mathrm{OI} 3$ & 0.746 & & & \\
\hline & OI4 & 0.851 & & & \\
\hline & OI5 & 0.777 & & & \\
\hline & OI6 & 0.678 & & & \\
\hline \multirow{8}{*}{$\begin{array}{l}\text { Communal } \\
\text { Orientation }\end{array}$} & $\mathrm{CO} 1$ & 0.794 & \multirow{8}{*}{0.563} & \multirow{8}{*}{0.911} & \multirow{8}{*}{0.887} \\
\hline & $\mathrm{CO} 2$ & 0.769 & & & \\
\hline & $\mathrm{CO} 3$ & 0.856 & & & \\
\hline & $\mathrm{CO} 4$ & 0.780 & & & \\
\hline & $\mathrm{CO} 5$ & 0.791 & & & \\
\hline & $\mathrm{CO} 7$ & 0.653 & & & \\
\hline & CO9 & 0.685 & & & \\
\hline & $\mathrm{CO} 10$ & 0.648 & & & \\
\hline \multicolumn{2}{|c|}{ Gender } & 1.000 & 1.000 & 1.000 & 1.000 \\
\hline \multicolumn{2}{|c|}{ Moderasi } & 0.993 & 1.000 & 1.000 & 1.000 \\
\hline
\end{tabular}

Tabel 5. Hasil Analisis $R^{2}$ dan $Q^{2}$

\begin{tabular}{|c|c|c|}
\hline Variabel & R-Square & Predictive Relevance \\
\hline Communal Orientation & 0,083 & 0.040 \\
\hline Leadership Aspiration & 0,664 & 0.346 \\
\hline
\end{tabular}

Tabel 6. Hasil PLS Algorithm dan Bootstraping

\begin{tabular}{|c|c|c|c|}
\hline Hubungan & Path Coefficients & t-statistics & p-value \\
\hline $\mathrm{G} \rightarrow \mathrm{CO}$ & 0.288 & 2.754 & 0.006 \\
\hline $\mathrm{CO} \rightarrow \mathrm{LA}$ & 0.325 & 5.759 & 0.000 \\
\hline $\mathrm{G} \rightarrow \mathrm{LA}$ & 0.094 & 2.529 & 0.011 \\
\hline $\mathrm{OI} \rightarrow \mathrm{LA}$ & 0.615 & 9.598 & 0.000 \\
\hline
\end{tabular}




\begin{tabular}{|c|c|c|c|}
\hline $\mathrm{M} \rightarrow \mathrm{LA}$ & -0.221 & 3.923 & 0.000 \\
\hline $\mathrm{G} \rightarrow \mathrm{CO} \rightarrow \mathrm{LA}$ & 0.094 & 2.529 & 0.011 \\
\hline
\end{tabular}

\section{DISKUSI}

Berdasarkan hasil analisis, maka dapat disimpulkan bahwa (H1) gender memiliki pengaruh yang positif terhadap communal orientation, (H2) communal orientation memiliki pengaruh yang positif terhadap leadership aspiration, (H3) gender memiliki pengaruh yang positif terhadap leadership aspiration melalui mediasi dari communal orientation, (H4) organizational identification memiliki pengaruh yang positif terhadap leadership aspiration, dan (H5) organizational identification memoderasi hubungan communal orientation dan leadership aspiration.

Berdasarkan penelitian yang telah dilakukan, Gender terbukti mampu memprediksi communal orientation pekerja kedai kopi di Jakarta Utara, dan communal orientation terbukti mampu memprediksi leadership aspiration pekerja kedai kopi di Jakarta Utara. Oleh sebab itu, peneliti menyarankan para pebisnis kedai kopi untuk memperhatikan gender dalam menerima karyawannya. Selain itu, organizational identification terbukti mampu memprediksi leadership aspiration serta memoderasi hubungan antara communal orientation dan leadership aspiration. Oleh sebab itu, peneliti menyarankan pebisnis kedai kopi untuk menjalin dan membangun hubungan yang baik dengan karyawannya, agar para pekerja kedai kopi memiliki organizational identification yang tinggi kepada perusahaan.

\section{PENUTUP}

Hasil penelitian menunjukkan bahwa gender mampu mempengaruhi leadership aspiration baik melalui mediasi oleh communal orientation maupun tidak melalui mediasi. Organizational identification juga dapat mempengaruhi leadership aspiration baik secara langsung maupun berupa efek moderasi terhadap pengaruh communal orientation terhadap leadership aspiration. Bagi peneliti lain, peneliti menyarankan untuk menggunakan variabel lain di luar penelitian yang mampu menjelaskan communal orientation secara lebih baik, dikarenakan $91,7 \%$ dari variabel communal orientation dapat dijelaskan oleh variabel lainnya di luar penelitian. Peneliti juga menyarankan untuk memperluas jangkauan penelitian dan menambah jumlah responden dengan memperhatikan distribusi karakteristik responden sehinggal hasil penelitian lebih representatif. Peneliti juga menyarankan untuk menggunakan variabel-variabel lainnya di luar penelitian yang mampu menjelaskan leadership aspiration secara lebih baik, dikarenakan 33,6\% dari variabel leadership aspiration dapat dijelaskan oleh variabel lainnya di luar penelitian. Terakhir, peneliti menyarankan untuk meneliti industri lain yang berbeda untuk mengetahui apakah hasil penelitian ini dapat digunakan untuk industri lainnya atau tidak.

\section{DAFTAR PUSTAKA}

Abele, A.E. (2003). The dynamics of masculine-agentic and feminine-communal traits: findings from a prospective study. Journal of Personality and Social Psychology, 85(4), 768-776.

Aritonang, L.R. (2007). Riset Pemasaran: Teori dan Praktik. Bogor: Ghalia Indonesia. 
Ashforth, B.E. (2001). Role Transitions in Organizational Life: An Identity-Based Perspective. Malwah: Routledge.

Ashforth, B.E., Harrison, S.H. \& Corley, K.G. (2008). Identification in organizations: an examination of four fundamental questions. Journal of Management, 34(3), 325-374.

Avanzi, L., Schuh, S.C., Fraccaroli, F. \& van Dick, R. (2015). Why does organizational identification relate to reduced employee burnout? The mediating influence of social support and collective efficacy. Work and Stress, 29(1), 1-10.

Baron, A.R. (Alih Bahasa Ratna Juwita) (2000). Psikologi Sosial. Bandung: Khazanah Intelektual.

Bass, B.M. \& Stogdill, R.M. (1990). Bass and Stogdill's Handbook of Leadership: Theory, Research, and Managerial Applications. New York: Simon and Schuster.

Bisnis. (2019) Industri Kedai Kopi Ditaksir Tumbuh 20\% Tahun Ini (Retrieved from: https://ekonomi.bisnis.com/19-10-2019)

Boatwright, K.J. \& Egidio, R.K. (2003). Psychological predictors of college women's leadership aspirations. Journal of College Student Development, 44(5), 653-669.

Carli, L.L. \& Eagly, A.H. (2016). Women face a labyrinth: an examination of metaphors for women leaders. Gender in Management: An International Journal, 31(8), 514527.

Clark. M.S., Ouellette, R., Powell, M.C., \& Milberg, S. (1987). Recipient's Mood, Relationship Type, and Helping. Journal of Personality and Social Psychology, 53(1), 94-103.

Demir, M., Demir, S.S. \& Nield, K. (2015). The relationship between person-organization fit, organizational identification and work outcomes. Journal of Business Economics and Management, 16(2), 369-386.

Dukerich, J.M., Golden, B.R. \& Shortell, S.M. (2002). Beauty is in the eye of the beholder: the impact of organizational identification, identity, and image on the cooperative behaviors of physicians. Administrative Science Quarterly, 47(3), 507-533.

Eagly, A.H. (1987), Sex Differences in Social Behavior: A Social-Role Interpretation. Hillsdale: Psychology Press.

Fakih, M. (2006). Analisis Gender dan Transformasi Sosial. Yogyakarta: Pustaka Pelajar.

Gebauer, J.E., Paulhus, D.L. \& Neberich, W. (2013). Big two personality and religiosity across cultures: communals as religious conformists and agentics as religious contrarians. Social Psychological and Personality Science, 4(1), 21-30.

Harvey, T.R. (2007). African American Women's Career Development: The Role of Self

Efficacy as A Mediator of Leadership Aspirations. Disertasi (Tidak diterbitkan). The Pennsylvania State University, United States.

International Coffee Organization. (2017) Annual Review (Retrieved from: http://www.ico.org/19-10-2019)

Kompas. (2018) Jumlah Kartini Indonesia di Posisi Manajemen Senior Perusahaan Tertinggi di Asia Pasifik (Retrieved from: https://ekonomi.kompas.com/2-7-2019)

Kornferry. (2016) Your Leadership Aspiration (Retrieved from: http://static.kornferry.com/15-9-2019)

Kumparan. (2019) Perempuan dan Perannya di Garda Depan Industri Kopi (Retrieved from: https://kumparan.com/19-10-2019)

Lee, E.S., Park, T.Y. \& Koo, B. (2015). Identifying organizational identification as a basis for attitudes and behaviors: a meta-analytic review. American Psychological Association, 141(5), 1049-1080. 
LinkedIn. (2016) The 4 Aspirations of Great Leaders (Retrieved from: https://www.linkedin.com/15-9-2019)

Locke, K.D., Craig, T., Baik, K.D. \& Gohil, K. (2012). Binds and bounds of communion: effects of interpersonal values on assumed similarity of self and others. Journal of Personality and Social Psychology, 103(5), 879-897.

Lyness, K.S. \& Heilman, M.E. (2006). When fit is fundamental: performance evaluations and promotions of upper-level female and male managers. Journal of Applied Psychology, 91(4), 777-785.

Mael, F.A. \& Ashforth, B.E. (1992). Alumni and their alma mater: a partial test of the reformulated model of organizational identification. Journal of Organizational Behavior, 13(2), 103-123.

Mael, F.A. \& Ashforth, B.E. (1995). Loyal from day one: biodata, organizational identification, and turnover among newcomers. Personnel Psychology, 48(2), 309333.

Malhotra, N.K. (2004). Marketing Research: an Applied Orientation. New Jersey: Prentice-Hall.

Riketta, M. (2005). Organizational identification: a meta-analysis. Journal of Vocational Behavior, 66(2), 358-384.

Sadli, S. \& Bachtiar, I. (2010). Berbeda Tetapi Setara: Pemikiran Tentang Kajian Perempuan. Jakarta: Penerbit Buku Kompas.

Santrock, J.W. (2002). Life Span Development: Perkembangan Masa Hidup. Jakarta: Erlangga.

Sasame Coffee. (2019) Kenali Pengertian, Tugas, dan Tips Menjadi Barista Kopi (Retrieved from: https://www.sasamecoffee.com/19-10-2019)

Siagian, S.P. (1994). Teori dan Praktek Kepemimpinan. Jakarta: Rineka Cipta.

Singer, M. (1991). The relationship between employee sex, length of service and leadership aspirations: a study from valence, self-efficacy and attribution perspectives. Applied Psychology, 40(4), 417-436.

van Dick, R., Christ, O., Stellmacher, J., Wagner, U., Ahlswede, O., Grubba, C. \& Tissington, P.A. (2004). Should I stay or should I go? Explaining turnover intentions with organizational identification and job satisfaction. British Journal of Management, 15(4), 351-360.

van Knippenberg, D. \& Fritz, C. (2017). Gender and leadership aspiration: the impact of organizational identification. Leadership \& Organization Development Journal, 38(8), 1018-1037.

van Knippenberg, D. \& van Schie, E.C.M. (2000). Foci and correlates of organizational identification. Journal lof Occupational and Organizational psychology, 73(2), 137147.

van Knippenberg, D. (2000). Work motivation and performance: a social identity perspective. Applied Psychology, 49(3), 357-371.

Very Well Mind. (2019) The Major Leadership Theories (Retrieved from: https://www.verywellmind.com/7-10-2019)

Wegge, J., van Dick, R., Fisher, G.K., Wecking, C. \& Moltzen, K. (2006). Work motivation, organisational identification, and well-being in call centre work. Work and Stress, 20(1), 60-83. 
Wilson, N. \& Keni (2018). Pengaruh Website Design Quality dan Kualitas Jasa Terhadap Repurchase Intention: Variabel Trust Sebagai Variabel Mediasi. Jurnal Manajemen dan Pemasaran Jasa, 11(2), 291-310.

Wilson, N. (2018). The Impact of Service Quality and Brand Image toward Customer Loyalty in the Indonesian Airlines Industry. Jurnal Manajemen Indonesia, 18(3), 222-234. 